\title{
RESEARCH
}

Open Access

\section{Associations of linoleic acid with markers of glucose metabolism and liver function in South African adults}

Kamalita Pertiwi ${ }^{1 *}\left(\mathbb{D}\right.$, Leanne K. Küpers ${ }^{1}$, Johanna M. Geleijnse ${ }^{1}$, Peter L. Zock ${ }^{1,2}$, Anne J. Wanders²,

Herculina S. Kruger ${ }^{3}$, Tertia van Zyl $\left.\right|^{3}$, Iolanthé M. Kruger ${ }^{4}$ and Cornelius M. Smuts ${ }^{3}$

\begin{abstract}
Background: The relation between dietary and circulating linoleic acid (18:2 n-6, LA), glucose metabolism and liver function is not yet clear. Associations of dietary and circulating LA with glucose metabolism and liver function markers were investigated.

Methods: Cross-sectional analyses in 633 black South Africans (aged > 30 years, 62\% female, 51\% urban) without type 2 diabetes at baseline of the Prospective Urban Rural Epidemiology study. A cultural-sensitive 145-item foodfrequency questionnaire was used to collect dietary data, including LA (percentage of energy; en\%). Blood samples were collected to measure circulating LA (\% total fatty acids (FA); plasma phospholipids), plasma glucose, glycosylated hemoglobin (HbA1c), serum gamma-glutamyl transferase (GGT), alanine (ALT) and aspartate aminotransferase (AST). Associations per 1 standard deviation (SD) and in tertiles were analyzed using multivariable regression.
\end{abstract}

Results: Mean $( \pm$ SD) dietary and circulating LA was $6.8( \pm 3.1)$ en\% and $16.0( \pm 3.5) \%$ total FA, respectively. Dietary and circulating LA were not associated with plasma glucose or HbA1c ( $\beta$ per 1 SD: -0.005 to $0.010, P>0.20$ ). Higher dietary LA was generally associated with lower serum liver enzymes levels. One SD higher circulating LA was associated with $22 \%$ lower serum GGT ( $\beta$ (95\% confidence interval): $-0.25(-0.31,-0.18), P<0.001)$, but only $\leq 9 \%$ lower for ALT and AST. Circulating LA and serum GGT associations differed by alcohol use and locality.

Conclusion: Dietary and circulating LA were inversely associated with markers of impaired liver function, but not with glucose metabolism. Alcohol use may play a role in the association between LA and liver function.

Trial registration: PURE North-West Province South Africa study described in this manuscript is part of the PURE study. The PURE study is registered in ClinicalTrials.gov (Identifier: NCT03225586; URL).

Keywords: Linoleic acid, Polyunsaturated fatty acids, Gamma-glutamyl transferase, Liver enzymes, Glycemia, African, Alcohol intake

\footnotetext{
* Correspondence: kamalita.pertiwi@wur.nl

'Division of Human Nutrition and Health, Wageningen University, Wageningen, The Netherlands

Full list of author information is available at the end of the article
}

(c) The Author(s). 2020 Open Access This article is licensed under a Creative Commons Attribution 4.0 International License, which permits use, sharing, adaptation, distribution and reproduction in any medium or format, as long as you give appropriate credit to the original author(s) and the source, provide a link to the Creative Commons licence, and indicate if changes were made. The images or other third party material in this article are included in the article's Creative Commons licence, unless indicated otherwise in a credit line to the material. If material is not included in the article's Creative Commons licence and your intended use is not permitted by statutory regulation or exceeds the permitted use, you will need to obtain permission directly from the copyright holder. To view a copy of this licence, visit http://creativecommons.org/licenses/by/4.0/ The Creative Commons Public Domain Dedication waiver (http://creativecommons.org/publicdomain/zero/1.0/) applies to the data made available in this article, unless otherwise stated in a credit line to the data. 


\section{Introduction}

Circulating linoleic acid (18:2 n-6, LA) has been inversely associated with the risk of type 2 diabetes (T2D) in cohorts of mostly healthy Caucasian populations [1], whereas the association between dietary linoleic acid and T2D risk remains equivocal [2-5]. This discrepancy has been mainly attributed to the limitation of self-reported dietary LA assessment. However, endogenous fatty acids (FA) metabolism affecting circulating LA proportion may also play a role.

The proportion of circulating LA is not only influenced by dietary LA, but also by endogenous FA metabolism, which may be affected by various factors such as obesity and liver impairment [6, 7]. A lower circulating LA was observed in non-alcoholic fatty liver disease patients as compared to healthy individuals [8]. Circulating LA has also been inversely associated with hepatic fat deposition [9]. These findings suggest that low proportions of circulating LA may indicate impairment of liver function.

The influence of dietary LA on glucose metabolism and liver function is not yet clear. Meta-analyses of randomized controlled feeding trials showed that increasing the intake of polyunsaturated fatty acids (PUFA) (mainly LA) potentially affects glucose metabolism $[10,11]$. On the other hand, a high dietary n- 6 FA or $n-6 / n-3$ ratio has been considered to promote the development of fatty liver through inflammation [12], although evidence from two systematic reviews and meta-analyses of randomized controlled trials in humans showed that increasing dietary n-6 FA did not result in higher concentration of inflammatory markers [13, 14].

Studies on LA and markers related to T2D risk have been performed mainly in Caucasian populations. Populations with African ancestry may have different distributions of genetic variants related to long-chain PUFA metabolism [15]. Therefore, this study aimed to investigate associations of both dietary and circulating LA with markers of glucose metabolism and liver function in the South African leg of the Prospective Urban and Rural Epidemiological (PURE) study.

\section{Subjects and methods Study population}

The PURE North-West Province South Africa (PURENWP-SA) is a cohort of black South African participants and part of the larger international PURE study. The design, selection and recruitment of participants for the PURE-NWP-SA study have been described previously [16]. In brief, apparently healthy black South African adults aged > 30 years old were recruited from two urban and two rural communities in North-West Province. Of 3750 adults who completed the screening questionnaire, 2010 attended baseline measurements in 2005. All participants gave written consent to participation and the study was approved by the Ethics Committee of the North-West University (04 M10 and NW-00016-10-A1) [16].

Baseline PURE-NWP-SA cohort data were used for the present cross-sectional study. Participants without information on dietary LA intake or with implausible energy intake $(<3347 \mathrm{~kJ}(\mathrm{~kJ})[<800 \mathrm{kcal}(\mathrm{kcal})]$ or $>16,736 \mathrm{~kJ}$ [> $4000 \mathrm{kcal}]$ for men; $<2092 \mathrm{~kJ}[<500 \mathrm{kcal}]$ or $>14,644 \mathrm{~kJ}[>$ $3500 \mathrm{kcal}$ ] for women) [17] or missing plasma FA were further excluded. Missing or unreliable plasma glucose (values $<2.5 \mathrm{mmol} / \mathrm{L}$ ) and glycosylated hemoglobin (HbA1c) were excluded. Finally, participants with prevalent diabetes, defined as self-reported diagnosis of type 2 diabetes or use of anti-diabetes drugs, were excluded. A total of 633 participants were included in the present analyses (Additional file 1: Figure S1).

\section{Dietary assessment}

Information on usual diet was collected with a culturalsensitive 145-item quantified food-frequency questionnaire (QFFQ). This questionnaire, covering dietary intake in the previous month, was developed and validated in a similar population [18-20]. Dietary FA intakes at baseline (expressed as grams/day (g/d) and a percentage of energy (en\%)) were calculated by using the South African food composition database [21]. In addition, information from the QFFQ and food composition database were used to calculate total daily intakes of energy $(\mathrm{kJ})$, macronutrients (en\%), dietary fiber $(\mathrm{g} / \mathrm{d})$ and cholesterol $(\mathrm{mg} / \mathrm{d})$.

\section{Circulating plasma phospholipid FA measurement}

Venous blood samples were collected from participants after $8-10 \mathrm{~h}$ of fasting by a trained nurse, prepared in conditions required for further processing and stored at $-80{ }^{\circ} \mathrm{C}$ until analysis [16]. Before analysis, frozen EDTA samples were thawed and total lipids were extracted by using a modified Folch method [22] from the plasma samples. Phospholipids FA fraction was isolated by using thin-layer chromatography. FA composition of plasma phospholipids was analyzed using quadrupole gas chromatography electron ionization mass spectrometry at the Centre of Excellence for Nutrition laboratory, Potchefstroom, South Africa as previously described in detail [23]. A total of $26 \mathrm{FA}$ were quantified as a percentage of total FA identified in the sample (g/100 g total FA; \% total FA) including LA and arachidonic acid (20:4n-6). Delta-6-desaturase activity was also estimated by calculating the ratio of circulating dihomo-gamma-linolenic acid to LA (20:3n-6/18:2n-6).

\section{Markers of glucose metabolism and liver function}

Plasma glucose $(\mathrm{mmol} / \mathrm{L})$ in the fasting state was measured by using Synchron ${ }^{\circledR}$ System (Beckman Coulter Co., 
Fullerton, CA, USA). HbA1c was assessed in EDTAtreated whole blood by using a D-10 Hemoglobin testing system (Bio-Rad Laboratories, Hercules, CA, USA). Serum liver enzymes (gamma-glutamyl transferase (GGT), alanine aminotransferase (ALT), aspartate aminotransferase (AST); U/L) were determined using Sequential Multiple Analyzer Computer Konelab20i auto analyzer (Thermo Fischer Scientific, Vantaa, Finland).

\section{Other measurements}

Information about demographics, socioeconomic status, lifestyle and physical activity was collected using structured questionnaires that were standardized for the international PURE study [16]. Locality was identified as rural or urban based on the communities where the participants resided. Physical activity index (PAI) was calculated (maximum score of 10.0) and participants were categorized into having 'low' $(1<\mathrm{PAI} \leq 3.33)$, 'moderate' $(3.34 \leq \mathrm{PAI} \leq$ 6.67 ), or 'high' (PAI $\geq 6.68$ ) physical activity $[24,25]$. Participants had to indicate their level of education obtained and their responses were recoded into a dichotomous variable of 'no school or primary' or 'secondary or higher'. Participants' smoking status was recorded as 'non-smoker' or 'past or current smoker'. Alcohol intake was assessed by using the QFFQ and expressed as $\mathrm{g} / \mathrm{d}$ of pure ethanol [26]. Alcohol intake was also categorized into 'no' $(0 \mathrm{~g} / \mathrm{d})$, 'light'(> 0-10 g/d (women); > 0-20 g/d (men)), 'moderate' (>10-20 g/d (women); > 20-30 g/d (men)), or 'high'(> 20 g/d (women); > $30 \mathrm{~g} / \mathrm{d}$ (men)).

Height, weight and waist circumference were measured using standardized procedure as described previously [16]. Body mass index (BMI) was calculated by dividing weight by height squared $\left(\mathrm{kg} / \mathrm{m}^{2}\right)$. Obesity was considered present when BMI $\geq 30 \mathrm{~kg} / \mathrm{m}^{2}$. Other biochemical analyses such as total cholesterol (mmol/L), high-density lipoprotein cholesterol (HDL-C; mmol/L), triglycerides (TG; $\mathrm{mmol} / \mathrm{L})$, high-sensitivity C-reactive protein $(\mathrm{mg} / \mathrm{L})$ were determined in serum [27]. Interleukin-6 (pg/ml) was measured using ultrasensitive enzyme immunoassays (Elecsys 2010, Roche, Basel, Switzerland) [28]. Low-density lipoprotein cholesterol (LDL-C; $\mathrm{mmol} / \mathrm{L}$ ) was estimated using the equation: LDL-C = total cholesterol - HDL-C - triglycerides/adjustable factor. In this modification of the Friedewald equation specific adjustable factors are used to estimate VLDL-C, depending on the levels of triglycerides and non-HDL-C [29]. Values of serum HDL-C $\leq 1.0 \mathrm{mmol} / \mathrm{L}$ for men or $\leq 1.3 \mathrm{mmol} / \mathrm{L}$ for women were considered low and serum triglycerides $>1.7 \mathrm{mmol} / \mathrm{L}$ was considered as high. Systolic and diastolic blood pressure (in $\mathrm{mmHg}$ ) were measured twice on the right upper arm in a seating position with 5 min between measurements as previously reported [27]. Use of medications (anti-diabetes, anti-hypertensive drug) was recorded at study sites by interviewers. Hypertension was considered present if blood pressure was $\geq 140 / 90 \mathrm{mmHg}$ or using antihypertensive medication. The human immunodeficiency virus (HIV) status of participants was assessed according to the South African National Department of Health protocol as previously described [16].

\section{Statistical analysis}

Participants' characteristics were examined in the total sample and by categorizing the participants into tertiles according to their dietary or circulating LA values. Linear trends across dietary or circulating LA were calculated by assigning median values of dietary or circulating LA for the tertile and modelling these as a continuous variable in the regression models. The distribution of values for all variables, the residuals and homogeneity of variances were examined before performing the main analyses. The outcome variables (plasma glucose, HbA1c, serum GGT, ALT and AST) were log-transformed before analysis to achieve normality of residuals and homogeneity of variances.

To assess the relationship between dietary and circulating LA, Spearman rank correlation (r) between dietary and circulating LA was calculated and adjusted for age, sex and total energy intake. Least-squares means and 95\% confidence interval (CI) of circulating LA (\% total FA) across tertiles of dietary LA (en\%) were calculated by using linear regression, adjusted for age, sex and total energy intake, also in subgroups by sex (men vs. women), age (< 65 vs. $\geq 65$ y), obesity (present vs. absent), glycemic status (plasma glucose $<6.1$ vs. $\geq 6.1$ $\mathrm{mmol} / \mathrm{L}$ ), and alcohol use ('no': intake $=0 \mathrm{~g} / \mathrm{d}$ vs. 'yes': intake $>0 \mathrm{~g} / \mathrm{d}$ ).

Association of dietary or circulating LA with glycemic and liver function measures were evaluated per $1 \mathrm{SD}$ and in dietary or circulating LA tertiles by using multivariable linear regression. Model 1 included age and sex. Model 2 was additionally adjusted for education level, locality, smoking status, physical activity, alcohol intake $(\mathrm{g} / \mathrm{d})$, total energy intake $(\mathrm{kJ} / \mathrm{d})$ and BMI $\left(\mathrm{kg} / \mathrm{m}^{2}\right)$. Model 3 was further adjusted for available carbohydrates (en\%), saturated FA (en\%), trans-FA (g/d) and dietary fiber (g/ d). Dietary factors were considered but not included in the fully adjusted model for circulating LA (model 2) because no indication was found for confounding of circulating LA associations by these factors. Missing values in covariables (education level, $n=15$; smoking status, $n=1$; physical activity, $n=22$ ) were imputed by using sex-specific modes. Potential effect modification by sex, age, locality, obesity, and alcohol use was evaluated by using stratified analyses and by including product terms in the fully adjusted model (model 3 for dietary LA and model 2 for circulating LA). Stratified analyses by alcohol use were conducted in two categories (yes vs. no) 
due to the relatively small sizes of moderate and high alcohol intake subgroups.

In sensitivity analyses, participants with a high alcohol intake (alcohol $>20 \mathrm{~g} / \mathrm{d}$ for women and $>30 \mathrm{~g} / \mathrm{d}$ for men), with liver enzymes values indicating possible alcohol abuse (serum GGT $>80 \mathrm{U} / \mathrm{L}$ and AST-to-ALT ratio $\geq 2: 1$ ) or having elevated plasma glucose (fasting plasma glucose $\geq 6.1 \mathrm{mmol} / \mathrm{L}$ ) were excluded. All analyses were performed in SAS version 9.4 (Cary, NC, USA). A two-sided $P$-value $<0.05$ was considered as statistically significant.

\section{Results}

The total sample of 633 subjects was on average 53 years, $63 \%$ was women and $51 \%$ resided in urban communities (Table 1). Fifty-eight percent of the participants were considered hypertensive and $43 \%$ had either high serum triglycerides or low HDL-C levels. Mean $( \pm \mathrm{SD})$ dietary LA intake was $6.8( \pm 3.1)$ en\% and circulating LA was $16.0( \pm 3.5) \%$ total FA. Liver function markers values were available for 613 participants (97\%), whose characteristics were not different from the total sample (Additional file 1: Table S1). The proportion of participants reporting no alcohol intake was lower in urban (48.6\%) than in rural communities (66.2\%), whereas proportions of participants with high alcohol intake and with obesity were similar in both communities (Additional file 1: Table S2).

Dietary LA was weakly associated with circulating LA $(r=0.14, \quad P<0.001)$. Margarine and vegetable oils, sources of dietary LA, were also associated with circulating LA with adjusted Spearman's correlations of 0.10 $(P=0.011)$ and $0.10(P=0.009)$, respectively (Additional file 1: Table S3). Dose-response associations of circulating with dietary LA intake were evident, despite differences in sex, age or presence of obesity. Dose-response associations were observed for participants with normal plasma glucose, but not in participants with elevated plasma glucose. Within categories of similar LA intake, individuals with alcohol intake $>0 \mathrm{~g} / \mathrm{d}$ had a lower mean circulating LA than individuals reporting no alcohol intake (Additional file 1: Figure S2).

\section{Dietary LA and glucose metabolism and liver function markers}

Participants with higher dietary LA had on average a higher BMI, were more likely to reside in urban communities and were less likely to consume alcohol than those with lower dietary LA (Table 2$)$. Mean $( \pm$ SD) circulating LA ranged from $15.5( \pm 3.5)$ to $16.4( \pm 3.5) \%$ total FA across dietary LA tertiles. Participants with higher dietary LA did not have significantly higher highsensitivity C-reactive protein, interleukin-6 or circulating arachidonic acid than those in the lower dietary LA tertiles (Table 2).

Dietary LA was not associated with plasma glucose or HbA1c after multivariable adjustments of demographic, lifestyle and dietary factors (Table 3). Participants in the highest dietary LA tertile had significantly lower geometric mean (95\% CI) serum GGT than participants in the lowest tertile (T3 vs. T1: $48.8(42.8,55.6)$ vs. 65.2 (57.0, $74.5), P$-trend $=0.008)$. Dietary LA was not significantly associated with serum ALT across tertiles (T3 vs. T1: $16.6(15.2,18.1)$ vs. $19.1(17.4,20.9), P$-trend $=0.06)$. Geometric mean serum AST was lower with higher dietary LA (T3 vs. T1: $25.0(22.8,27.5)$ vs. 30.2 (27.4, 33.2), $P$-trend $=0.018)$. In continuous analysis per one SD, however, the associations between dietary LA and logserum GGT, ALT or AST were not statistically significant (Table 3).

\section{Circulating LA and glucose metabolism and liver function markers}

Mean $( \pm$ SD) dietary LA ranged from $6.5( \pm 3.2)$ to $7.4( \pm$ 3.0) en\% across circulating phospholipids LA tertiles. Participants with higher circulating LA were younger and less likely to consume alcohol. Circulating LA was inversely associated with serum triglycerides and inflammatory markers C-reactive protein and interleukin-6 (Table 2).

Circulating LA was not significantly associated with plasma glucose or HbA1c (Table 4). One SD increase in circulating LA (3.5\% total FA) was associated with a 0.25 lower (95\% CI: $-0.31,-0.18 ; P<0.001$ ) log-serum GGT after adjustment for demographic and lifestyle factors, total energy intake and BMI (Table 4). Circulating LA was also inversely associated with log-serum ALT $(\beta=-$ 0.050 (95\% CI: $-0.096,-0.003), P=0.036)$ and AST $(\beta=-0.090$ (95\% CI: $-0.139,-0.041), P<0.001)$. In tertiles, circulating LA was also significantly inversely associated with serum GGT (T3 vs. T1: 42.3 (37.9, 47.2) vs. 77.2 (69.1, 86.4), P-trend $<0.001$ ) and AST (T3 vs. T1: $24.8(22.9,26.9)$ vs. $30.2(27.8,32.8)$, P-trend<0.001).

Associations of circulating LA with serum GGT were modified by alcohol use $(P<0.001)$ and locality $(P<$ 0.001). Stronger inverse associations of circulating LA with GGT were observed for participants who reported any alcohol consumption compared to those who reported no consumption, and for participants residing in the urban compared to those in the rural communities (Additional file 1: Table S4). Similar effect modification by locality was observed for associations of circulating LA with serum ALT $(P=0.006)$ and AST $(P=0.001)$.

\section{Sensitivity analysis}

Excluding participants reporting high alcohol intake did not appreciably change the results (Additional file 1: 
Table 1 Baseline characteristics of participants of PURE-NWP-SA included in the present analyses $(n=633)$

\begin{tabular}{|c|c|}
\hline & Total sample \\
\hline Age (y) & $53.0 \pm 10.4$ \\
\hline Men & $240(37.9)$ \\
\hline Body mass index $\left(\mathrm{kg} / \mathrm{m}^{2}\right)$ & $24.9 \pm 6.9$ \\
\hline Obesity & $143(22.6)$ \\
\hline Locality (urban) & $325(51.3)$ \\
\hline \multicolumn{2}{|l|}{ Education level $^{a}$} \\
\hline No school or primary & $247(40.0)$ \\
\hline Secondary or higher & $371(60.0)$ \\
\hline \multicolumn{2}{|l|}{ Smoking status ${ }^{a}$} \\
\hline Non-smoker & $284(44.9)$ \\
\hline Past or current smoker & $348(55.1)$ \\
\hline \multicolumn{2}{|l|}{ Physical activity ${ }^{a}$} \\
\hline Low & $5(0.8)$ \\
\hline Moderate & $265(43.4)$ \\
\hline High & $341(55.8)$ \\
\hline Fasting plasma glucose (mmol/L) & $4.90(4.40-5.40)$ \\
\hline $\mathrm{HbA1c}(\%)$ & $5.60(5.30-5.90)$ \\
\hline \multicolumn{2}{|l|}{ Serum lipids (mmol/L) } \\
\hline Total cholesterol & $5.19 \pm 1.31$ \\
\hline LDL cholesterol & $3.03 \pm 1.13$ \\
\hline HDL cholesterol & $1.58 \pm 0.64$ \\
\hline Triglycerides & $1.13(0.84-1.69)$ \\
\hline \multicolumn{2}{|l|}{ Liver enzymes activity (U/L) } \\
\hline Gamma-glutamyl transferase & $45.8(29.7-88.0)$ \\
\hline Alanine transaminase & $17.0(12.6-24.4)$ \\
\hline Aspartate aminotransferase & $25.0(18.8-35.0)$ \\
\hline HIV-positive ${ }^{a}$ & $5(0.8)$ \\
\hline \multicolumn{2}{|l|}{ Dietary variables } \\
\hline Daily total energy intake (kJ) & $7356 \pm 3031$ \\
\hline Available carbohydrate (en\%) & $58.8 \pm 9.2$ \\
\hline Protein (en\%) & $12.4 \pm 2.3$ \\
\hline Total fat (en\%) & $24.2 \pm 8.7$ \\
\hline Saturated fatty acids (en\%) & $5.9 \pm 3.0$ \\
\hline Monounsaturated fatty acids (en\%) & $6.4 \pm 3.3$ \\
\hline Polyunsaturated fatty acids (en\%) & $7.4 \pm 3.2$ \\
\hline $\mathrm{n}-3$ fatty acids $(\mathrm{mg} / \mathrm{d})^{\mathrm{a}}$ & $312(193-474)$ \\
\hline Trans-fatty acids (g/d) & $0.18(0.07-0.49)$ \\
\hline Dietary cholesterol (mg/d) & $149(82-251)$ \\
\hline Dietary fiber (g/d) & $20.4 \pm 9.2$ \\
\hline Alcohol consumption ${ }^{c}(\mathrm{~g} / \mathrm{d}$ ) & $0(0-12.3)$ \\
\hline No & $362(57.2)$ \\
\hline Light & $128(20.2)$ \\
\hline Moderate & $43(6.8)$ \\
\hline
\end{tabular}

Table 1 Baseline characteristics of participants of PURE-NWP-SA included in the present analyses $(n=633)$ (Continued)

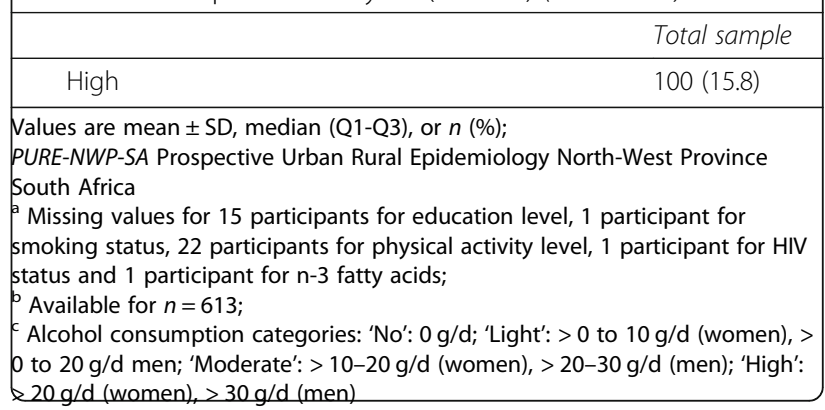

Table S5). When participants with an indication of alcohol abuse were excluded, associations of circulating LA with serum GGT, ALT and AST were attenuated (Additional file 1: Table S6). Exclusion of participants with elevated plasma glucose levels resulted in a significant inverse association of dietary LA with log-serum GGT; the $\beta$ (95\% CI) per one SD was $-0.105(-0.204$, $0.006 ; P=0.038)$ after exclusion as compared to -0.084 $(-0.179,0.010 ; P=0.08)$ before exclusion (Additional file 1: Table S7).

\section{Discussion}

In this cross-sectional study in 633 black South African men and women, dietary and circulating LA were not significantly associated with plasma glucose or HbAlc. However, both higher circulating and dietary LA were associated with lower levels of GGT. One SD higher circulating LA was associated with a $22 \%$ lower serum GGT and participants in the highest tertile of dietary LA had the lowest levels of serum GGT, a marker of liver function that is associated with insulin resistance and hepatic fat accumulation.

Only a few studies have reported on the relation of dietary and circulating LA with markers of glucose metabolism. As LA is the predominant type of dietary PUFA in many populations, including Africans [30], comparison of the results of the current study was also made with other studies using data on intake of $n-6$ or PUFA. The findings of no associations between dietary LA and glucose metabolism markers in the present study are in line with findings from previous studies in Caucasians. Dietary PUFA (mainly from plant source) was not associated with fasting glucose or HbA1c in 5675 Dutch men and women aged 45-65 years without diabetes [31]. Analyses of baseline data of two different trials in healthy middle-aged adults in Finland [32] and adults with metabolic syndrome in Spain [33] also showed no association of PUFA or LA intake with risk of impaired glucose metabolism. Two recent systematic reviews and meta-analyses of randomized controlled trials concluded that dietary n-6 or PUFA had some effect on insulin 
Table 2 Baseline characteristics of participants across tertiles of dietary and circulating linoleic acid

\begin{tabular}{|c|c|c|c|c|c|c|c|c|}
\hline & \multicolumn{3}{|c|}{ Dietary linoleic acid (en\%) } & \multirow[b]{2}{*}{$\begin{array}{l}P_{-} \\
\text {trend }^{a}\end{array}$} & \multicolumn{3}{|c|}{$\begin{array}{l}\text { Circulating linoleic acid } \\
\text { (\% total FA) }\end{array}$} & \multirow[b]{2}{*}{$\begin{array}{l}P_{-} \\
\text {trend }^{\mathrm{a}}\end{array}$} \\
\hline & $\begin{array}{l}\mathrm{T} 1 \\
(n=211)\end{array}$ & $\begin{array}{l}\mathrm{T} 2 \\
(n=211)\end{array}$ & $\begin{array}{l}\text { T3 } \\
(n=211)\end{array}$ & & $\begin{array}{l}\mathrm{T} 1 \\
(n=211)\end{array}$ & $\begin{array}{l}\mathrm{T} 2 \\
(n=211)\end{array}$ & $\begin{array}{l}\text { T3 } \\
(n=211)\end{array}$ & \\
\hline Median (range) & $3.9(0.4-5.3)$ & $6.7(5.4-8.0)$ & $9.6(8.0-18.4)$ & & $12.5(6.0-14.4)$ & $\begin{array}{l}16.0 \\
(14.4-17.7)\end{array}$ & $\begin{array}{l}19.5 \\
(17.7-25.7)\end{array}$ & \\
\hline Age (y) & $52.4 \pm 9.0$ & $52.8 \pm 11.3$ & $53.8 \pm 10.6$ & 0.18 & $53.8 \pm 9.4$ & $54.2 \pm 11.2$ & $50.9 \pm 10.1$ & 0.004 \\
\hline Men & $91(43.1)$ & 80 (37.9) & $69(32.7)$ & 0.09 & $76(36.0)$ & $82(38.9)$ & $82(38.9)$ & 0.78 \\
\hline Body mass index $\left(\mathrm{kg} / \mathrm{m}^{2}\right)$ & $23.8 \pm 6.5$ & $25.0 \pm 7.5$ & $25.9 \pm 6.7$ & 0.002 & $24.4 \pm 7.1$ & $25.2 \pm 7.4$ & $25.0 \pm 6.3$ & 0.36 \\
\hline Obesity & $40(19.0)$ & $47(22.3)$ & $56(26.5)$ & 0.17 & $40(19.0)$ & $52(24.6)$ & $51(24.2)$ & 0.30 \\
\hline Waist circumference (cm) & $79.6 \pm 12.3$ & $80.2 \pm 14.3$ & $81.3 \pm 12.1$ & 0.20 & $80.8 \pm 13.4$ & $80.6 \pm 13.5$ & $79.6 \pm 11.9$ & 0.36 \\
\hline Locality (urban) & $71(33.6)$ & $123(58.3)$ & $131(62.1)$ & $<0.001$ & $107(50.7)$ & $113(53.6)$ & $105(50.0)$ & 0.72 \\
\hline Education level $^{\mathrm{b}}$ & & & & 0.12 & & & & $<0.001$ \\
\hline No school or primary & $94(45.6)$ & $76(36.4)$ & $77(37.9)$ & & $108(51.9)$ & $78(38.2)$ & $61(29.6)$ & \\
\hline Secondary or higher & $112(54.4)$ & $133(63.6)$ & $126(62.1)$ & & $100(48.1)$ & $126(61.8)$ & $145(70.4)$ & \\
\hline Smoking status ${ }^{\mathrm{b}}$ & & & & 0.008 & & & & 0.010 \\
\hline Non-smoker & $84(40.0)$ & $87(41.2)$ & $113(53.6)$ & & $81(38.4)$ & $92(43.6)$ & $111(52.9)$ & \\
\hline Past or current smoker & $126(60.0)$ & $124(58.8)$ & $98(46.4)$ & & $130(61.6)$ & $119(56.4)$ & $99(47.1)$ & \\
\hline Physical activity ${ }^{b}$ & & & & $<0.001$ & & & & 0.006 \\
\hline Low & $1(0.5)$ & $3(1.5)$ & $1(0.5)$ & & $1(0.5)$ & $2(1.0)$ & $2(1.0)$ & \\
\hline Moderate & $66(32.4)$ & $100(49.0)$ & $99(48.8)$ & & $107(52.4)$ & $87(42.4)$ & $71(35.2)$ & \\
\hline High & $137(67.2)$ & $101(49.5)$ & $103(50.7)$ & & $96(47.1)$ & $116(56.6)$ & $129(63.9)$ & \\
\hline \multicolumn{9}{|l|}{ Serum lipids (mmol/L) } \\
\hline Total cholesterol & $5.10 \pm 1.33$ & $5.18 \pm 1.31$ & $5.28 \pm 1.30$ & 0.16 & $5.13 \pm 1.31$ & $5.34 \pm 1.37$ & $5.10 \pm 1.25$ & 0.81 \\
\hline LDL-C & $2.92 \pm 1.16$ & $3.01 \pm 1.14$ & $3.15 \pm 1.08$ & 0.047 & $2.87 \pm 1.08$ & $3.15 \pm 1.18$ & $3.06 \pm 1.11$ & 0.09 \\
\hline $\mathrm{HDL}-\mathrm{C}$ & $1.60 \pm 0.71$ & $1.61 \pm 0.60$ & $1.55 \pm 0.59$ & 0.42 & $1.65 \pm 0.72$ & $1.60 \pm 0.61$ & $1.49 \pm 0.56$ & 0.012 \\
\hline Triglycerides & $\begin{array}{l}1.06 \\
(0.85-1.62)\end{array}$ & $\begin{array}{l}1.07 \\
(0.82-1.69)\end{array}$ & $\begin{array}{l}1.20 \\
(0.86-1.78)\end{array}$ & 0.09 & $\begin{array}{l}1.17 \\
(0.86-1.85)\end{array}$ & $\begin{array}{l}1.15 \\
(0.85-1.65)\end{array}$ & $\begin{array}{l}1.04 \\
(0.80-1.53)\end{array}$ & $<0.001$ \\
\hline $\begin{array}{l}\text { High sensitivity C-reactive } \\
\text { protein }(\mathrm{mg} / \mathrm{L})\end{array}$ & $3.9(1.3-10.0)$ & $3.2(1.0-9.5)$ & $3.8(1.2-11.4)$ & 0.67 & $4.1(1.4-14.0)$ & $3.6(1.5-9.2)$ & $3.5(0.9-8.8)$ & 0.014 \\
\hline Interleukin-6 (pg/mL) & $\begin{array}{l}3.04 \\
(1.58-7.29)\end{array}$ & $\begin{array}{l}3.00 \\
(0.75-4.91)\end{array}$ & $\begin{array}{l}2.94 \\
(0.75-5.54)\end{array}$ & 0.13 & $\begin{array}{l}4.50 \\
(1.98-8.83)\end{array}$ & $\begin{array}{l}2.86 \\
(0.76-5.12)\end{array}$ & $\begin{array}{l}2.09 \\
(0.75-4.16)\end{array}$ & 0.002 \\
\hline HIV-positive & $2(1.0)$ & $0(0)$ & $3(1.4)$ & 0.38 & $2(1.0)$ & $0(0)$ & $3(1.4)$ & 0.30 \\
\hline \multicolumn{9}{|l|}{ Dietary variables $^{c}$} \\
\hline Total energy intake $(\mathrm{kJ} / \mathrm{d})$ & $7413 \pm 3265$ & $7338 \pm 2979$ & $7319 \pm 2846$ & 0.75 & $7699 \pm 3263$ & $7282 \pm 2920$ & $7088 \pm 2875$ & 0.038 \\
\hline Carbohydrate & $62.7 \pm 10.7$ & $59.3 \pm 7.4$ & $54.3 \pm 7.2$ & $<0.001$ & $57.8 \pm 9.5$ & $59.4 \pm 9.2$ & $59.1 \pm 9.0$ & 0.15 \\
\hline Protein & $11.4 \pm 2.3$ & $12.8 \pm 2.1$ & $13.1 \pm 2.1$ & $<0.001$ & $12.0 \pm 2.4$ & $12.7 \pm 2.2$ & $12.7 \pm 2.3$ & 0.001 \\
\hline Total fat & $16.4 \pm 6.1$ & $24.6 \pm 5.3$ & $31.7 \pm 6.9$ & $<0.001$ & $22.6 \pm 9.0$ & $24.0 \pm 8.6$ & $26.0 \pm 8.3$ & $<0.001$ \\
\hline Saturated FA & $3.9 \pm 2.4$ & $6.2 \pm 2.5$ & $7.6 \pm 2.9$ & $<0.001$ & $5.4 \pm 2.8$ & $5.9 \pm 3.0$ & $6.5 \pm 3.1$ & $<0.001$ \\
\hline Monounsaturated FA & $3.8 \pm 2.0$ & $6.6 \pm 2.4$ & $8.9 \pm 3.1$ & $<0.001$ & $5.8 \pm 3.1$ & $6.5 \pm 3.4$ & $7.0 \pm 3.3$ & $<0.001$ \\
\hline Polyunsaturated FA & $4.3 \pm 2.6$ & $7.2 \pm 1.1$ & $10.6 \pm 2.1$ & $<0.001$ & $7.1 \pm 3.7$ & $7.1 \pm 3.0$ & $7.9 \pm 3.0$ & 0.013 \\
\hline n-3 fatty acids (mg/d) & $\begin{array}{l}221.1 \\
(145.5-362.4)\end{array}$ & $\begin{array}{l}325.3 \\
(209.8-497.2)\end{array}$ & $\begin{array}{l}391.5 \\
(253.5-543.7)\end{array}$ & $<0.001$ & $\begin{array}{l}296.0 \\
(182.2-452.5)\end{array}$ & $\begin{array}{l}319.6 \\
(207.5-487.2)\end{array}$ & $\begin{array}{l}319.9 \\
(192.6-476.2)\end{array}$ & 0.37 \\
\hline Trans-FA (g/d) & $\begin{array}{l}0.09 \\
(0.03-0.25)\end{array}$ & $\begin{array}{l}0.20 \\
(0.08-0.48)\end{array}$ & $\begin{array}{l}0.33 \\
(0.12-0.68)\end{array}$ & $<0.001$ & $\begin{array}{l}0.18 \\
(0.07-0.43)\end{array}$ & $\begin{array}{l}0.17 \\
(0.06-0.48)\end{array}$ & $\begin{array}{l}0.19 \\
(0.07-0.53)\end{array}$ & 0.71 \\
\hline Total fiber (g/d) & $20.4 \pm 9.0$ & $21.1 \pm 9.3$ & $19.9 \pm 9.1$ & 0.55 & $20.3 \pm 9.0$ & $20.4 \pm 8.6$ & $20.6 \pm 9.9$ & 0.75 \\
\hline Dietary cholesterol (mg/d) & $90(48-159)$ & 159 (99-268) & $204(129-307)$ & $<0.001$ & $151(78-248)$ & 148 (90-246) & $143(81-254)$ & 0.56 \\
\hline Alcohol use: yes ${ }^{d}$ & $118(55.9)$ & $84(39.8)$ & 69 (32.7) & $<0.001$ & $117(55.4)$ & $88(41.7)$ & 66 (31.3) & $<0.001$ \\
\hline
\end{tabular}


Table 2 Baseline characteristics of participants across tertiles of dietary and circulating linoleic acid (Continued)

\begin{tabular}{|c|c|c|c|c|c|c|c|c|}
\hline & \multicolumn{3}{|c|}{ Dietary linoleic acid (en\%) } & \multirow[b]{2}{*}{$\begin{array}{l}P- \\
\text { trend }^{\mathrm{a}}\end{array}$} & \multicolumn{3}{|c|}{$\begin{array}{l}\text { Circulating linoleic acid } \\
\text { (\% total FA) }\end{array}$} & \multirow[b]{2}{*}{$\begin{array}{l}P \text { - } \\
\text { trend }^{a}\end{array}$} \\
\hline & $\begin{array}{l}\mathrm{T} 1 \\
(n=211)\end{array}$ & $\begin{array}{l}\mathrm{T} 2 \\
(n=211)\end{array}$ & $\begin{array}{l}\text { T3 } \\
(n=211)\end{array}$ & & $\begin{array}{l}\mathrm{T} 1 \\
(n=211)\end{array}$ & $\begin{array}{l}\mathrm{T} 2 \\
(n=211)\end{array}$ & $\begin{array}{l}\text { T3 } \\
(n=211)\end{array}$ & \\
\hline$(g / d)$ & $4.6(0-36.2)$ & $0(0-11.6)$ & $0(0-4.3)$ & $<0.001$ & $2.9(0-27.0)$ & $0(0-8.6)$ & $0(0-5.8)$ & $<0.001$ \\
\hline \multicolumn{9}{|l|}{ Fatty acid composition } \\
\hline Arachidonic acid (20:4n-6), \% & $13.5 \pm 2.7$ & $13.4 \pm 2.5$ & $13.7 \pm 2.3$ & 0.43 & $12.9 \pm 2.9$ & $14.1 \pm 2.4$ & $13.6 \pm 2.0$ & 0.011 \\
\hline $\begin{array}{l}\text { Estimated D6D activity (20:3n-6/18:2n- } \\
\text { 6) }\end{array}$ & $0.200 \pm 0.061$ & $0.192 \pm 0.055$ & $0.187 \pm 0.058$ & 0.016 & $0.234 \pm 0.053$ & $0.196 \pm 0.047$ & $0.150 \pm 0.040$ & $<0.001$ \\
\hline
\end{tabular}

Values are mean $\pm \mathrm{SD}$, median $(\mathrm{Q} 1-\mathrm{Q} 3)$, or $n(\%)$ unless otherwise stated;

D6D Delta-6-desaturase, FA Fatty acids, HIV Human immunodeficiency virus

${ }^{a} P$-values for trend for continuous variables were obtained by assigning median value of dietary or circulating linoleic acid and this value was modelled as

continuous; for categorical variables $\mathrm{p}$-values from (exact) Chi-squared tests were displayed;

${ }^{\mathrm{b}}$ Missing values for 15 participants for education level, 1 participant for smoking status, 22 participants for physical activity level, 1 participant for HIV status, 1 participant for dietary n-3 fatty acids and 62 participants for interleukin-6;

' Dietary variables are expressed as percentage of energy unless otherwise stated;

${ }^{\mathrm{d}}$ Alcohol use: 'No': alcohol intake $=0 \mathrm{~g} / \mathrm{d}$, 'Yes' alcohol intake $>0 \mathrm{~g} / \mathrm{d}$;

concentration but little or no effect on fasting glucose $[11,34]$, also when plant-based PUFA replaced saturated fatty acids intake in populations without diabetes [11].

As with dietary LA, circulating LA was not associated with glucose metabolism markers in the present study. In contrast, the investigators of the Hoorn study of 667 Dutch Caucasian participants reported a weak inverse association between circulating LA in serum and plasma glucose. However, no association between circulating LA and HbA1c was observed in the Hoorn study [35], consistent with findings of the present study. In the Hoorn study, about half of the participants had impaired glucose metabolism [35], while in this current study only $9 \%$ had elevated plasma glucose. In normal glucose metabolism plasma glucose is under tight regulation [36], which may explain null findings in the current study.

For dietary LA, generally either no or weak associations with liver enzymes were observed in the present study. However, circulating LA was inversely associated with serum liver enzymes, most notably serum GGT. Concentrations of liver enzyme GGT have previously been associated with hepatic fat accumulation and insulin resistance [37, 38]. In the Coronary Artery Risk Development in Young Adults study (44\% black participants), mean dietary PUFA intake at baseline and year 7 tended also to be inversely related to serum GGT in year 10 of follow-up, although not statistically significant. However, there was no information on whether this association differed in the subgroup of black participants [39]. Results of a 10-week randomized controlled trial in Swedish individuals (15\% had diabetes) with abdominal obesity showed that intervention with a diet high in $\mathrm{n}-6$ PUFA (14 en\% from LA) resulted in lower liver fat as compared to an isocaloric diet high in saturated fatty acids [40]. In the present study, exclusion of participants with elevated plasma glucose resulted in a somewhat stronger inverse association of dietary LA with serum GGT.

No other study seems to have specifically examined the association of circulating LA and serum GGT, but there is some evidence that circulating LA could be associated with liver fat accumulation [9, 41, 42]. First, in the European Prospective Investigation into Cancer and Nutrition-Potsdam study, higher delta-6-desaturase activity, resulting in lower circulating LA, was associated with higher serum GGT [41]. The authors suggested that the association of delta-6-desaturase activity with T2D risk might be mediated by liver fat accumulation. Second, higher circulating LA was associated with lower visceral adipose tissue in a study of 287 elderly subjects, and also with lower fat in a subgroup of 73 of these subjects [9]. In another study in 24 overweight men, circulating LA was moderately inversely correlated with visceral fat thickness [42]. A possible mechanism relating LA to liver function is through its influence on de novo lipogenesis by attenuating effects of insulin on FA synthase activity and expression [43]. Another possible mechanism may be related to oxidative stress, as elevated serum GGT is a marker of high oxidative stress [44].

A weak association between dietary and circulating LA in the present study may partly explain the present study finding that dietary LA was weaker associated with GGT than circulating LA. It is possible that alcohol intake plays a role here. Previously, in a cohort of Dutch postmyocardial infarction patients, weak correlations of dietary with circulating LA and lower circulating LA with higher alcohol intakes at similar intakes of LA [45] were reported, which were also observed in the present study. High alcohol intake is an established cause of liver fat accumulation [46] and higher alcohol intake has been 
Table 3 Associations of dietary linoleic acid with glucose metabolism and liver function markers ${ }^{a, b}$

\begin{tabular}{|c|c|c|c|c|c|c|}
\hline & \multicolumn{3}{|c|}{ Tertiles of dietary linoleic acid } & \multirow{2}{*}{$\begin{array}{l}P \text { - } \\
\text { trend }^{c}\end{array}$} & \multirow[t]{2}{*}{$\beta(95 \% \mathrm{CI})$ per $1 \mathrm{SD}$} & \multirow[t]{2}{*}{$P$} \\
\hline & $\mathrm{T} 1$ & $\mathrm{~T} 2$ & T3 & & & \\
\hline \multicolumn{7}{|c|}{ Glucose metabolism markers } \\
\hline \multicolumn{7}{|c|}{ Plasma glucose, mmol/L } \\
\hline Model 1 & $4.88(4.73,5.03)$ & $4.84(4.69,4.99)$ & $4.92(4.77,5.07)$ & 0.71 & $0.008(-0.010,0.026)$ & 0.36 \\
\hline Model 2 & $4.90(4.74,5.06)$ & $4.83(4.68,4.98)$ & $4.91(4.76,5.06)$ & 0.89 & $0.007(-0.013,0.026)$ & 0.50 \\
\hline Model 3 & $4.90(4.72,5.06)$ & $4.83(4.68,4.98)$ & $4.91(4.76,5.06)$ & 0.93 & $0.010(-0.015,0.036)$ & 0.43 \\
\hline \multicolumn{7}{|l|}{$\mathrm{HbA1c}(\%)$} \\
\hline Model 1 & $5.61(5.51,5.70)$ & $5.66(5.56,5.76)$ & $5.67(5.57,5.77)$ & 0.39 & $0.004(-0.006,0.014)$ & 0.40 \\
\hline Model 2 & $5.64(5.54,5.74)$ & $5.65(5.56,5.75)$ & $5.65(5.55,5.75)$ & 0.89 & $0.001(-0.010,0.011)$ & 0.92 \\
\hline Model 3 & $5.60(5.49,5.71)$ & $5.65(5.56,5.75)$ & $5.68(5.57,5.80)$ & 0.36 & $0.008(-0.007,0.022)$ & 0.30 \\
\hline \multicolumn{7}{|c|}{ Liver function markers (subsample, $n=613$ ) } \\
\hline \multicolumn{7}{|c|}{ Serum GGT, U/L } \\
\hline Model 1 & $64.8(57.5,73.1)$ & $55.6(49.3,62.6)$ & $50.2(44.6,56.7)$ & 0.004 & $-0.079(-0.149,-0.010)$ & 0.025 \\
\hline Model 2 & $59.3(52.6,66.9)$ & $56.4(50.4,63.2)$ & $53.9(48.0,60.6)$ & 0.28 & $-0.006(-0.076,0.065)$ & 0.88 \\
\hline Model 3 & $65.2(57.0,74.5)$ & $57.0(50.9,63.7)$ & $48.8(42.8,55.6)$ & 0.008 & $-0.084(-0.179,0.010)$ & 0.08 \\
\hline \multicolumn{7}{|c|}{ Serum ALT, U/L } \\
\hline Model 1 & $19.0(17.6,20.5)$ & $17.2(16.0,18.6)$ & $16.8(15.6,18.2)$ & 0.027 & $-0.030(-0.074,0.014)$ & 0.18 \\
\hline Model 2 & $18.5(17.0,20.0)$ & $17.4(16.2,18.8)$ & $17.1(15.8,18.5)$ & 0.21 & $-0.005(-0.053,0.043)$ & 0.84 \\
\hline Model 3 & $19.1(17.4,20.9)$ & $17.4(16.2,18.8)$ & $16.6(15.2,18.1)$ & 0.06 & $-0.020(-0.084,0.044)$ & 0.54 \\
\hline \multicolumn{7}{|l|}{ Serum AST, U/L } \\
\hline Model 1 & $29.0(26.7,31.5)$ & $26.8(24.6,29.1)$ & $26.0(23.9,28.3)$ & 0.07 & $-0.022(-0.071,0.026)$ & 0.36 \\
\hline Model 2 & $28.3(26.0,30.9)$ & $26.7(24.6,28.9)$ & $26.6(24.5,28.9)$ & 0.33 & $0.004(-0.047,0.055)$ & 0.88 \\
\hline Model 3 & $30.2(27.4,33.2)$ & $26.7(24.6,28.9)$ & $25.0(22.8,27.5)$ & 0.018 & $-0.041(-0.109,0.027)$ & 0.24 \\
\hline
\end{tabular}

Values for outcome variables in dietary linoleic acid tertiles are geometric means and $95 \% \mathrm{Cl}$. Values for $\beta$ (95\% $\mathrm{Cl}$ ) are natural log-transformed values;

ALT Alanine aminotransferase, AST Aspartate aminotransferase, GGT Gamma-glutamyl transferase

a One standard deviation of dietary linoleic acid is 3.1 en\%;

${ }^{b}$ Multivariable models: Model 1: adjusted for age, sex; Model 2: model 1 plus education level, locality, smoking status, physical activity, alcohol intake, total energy intake, BMl; Model 3: model 2 plus fiber, available carbohydrates, saturated fatty acids, trans-fatty acids intake;

${ }^{c} P$-values for trend were obtained by assigning median value of dietary linoleic acid and and this value was modelled as continuous

associated with lower circulating LA in several crosssectional studies [47-49]. It is, therefore, possible that the inverse association between circulating LA and GGT in this study may reflect alcohol influence. However, when participants whose liver enzyme values indicated alcohol abuse were excluded, the associations of LA and serum GGT were somewhat attenuated but remained significant. This suggests that the observed association cannot be entirely explained by alcohol.

The stronger associations between LA and GGT in urban than in rural areas is difficult to explain. A possible explanation might be related to alcohol use in the current study population. The urbanization process in South Africa has been linked to a change in alcohol consumption pattern [50]. A difference in obesity status is not a likely explanation because average BMI and proportion of individuals with obesity in urban and rural communities were similar.

\section{Study strengths and limitations}

A novel aspect of the present study is the investigation on the associations of LA with glucose metabolism and liver function in a black South African population, while most other studies investigated white Caucasian populations. The current finding that LA was inversely associated with serum GGT may be relevant because the Atherosclerosis Risk in Communities study [51] showed that GGT is a strong predictor of T2D risk in a black population as compared to ALT or AST.

The present study also contributes to evidence on the relation of dietary fat quality with T2D risk in South Africans. The current recommendation for South Africans is to consume 5-8\% energy from n-6 PUFA [52]. Intake in the population seems to be within this range, which was confirmed by the data in the present study. However, most of the evidence underlying the South African 
Table 4 Associations of circulating linoleic acid with glucose metabolism and liver function markers ${ }^{a, b}$

\begin{tabular}{|c|c|c|c|c|c|c|}
\hline & \multicolumn{3}{|c|}{ Tertiles of circulating linoleic acid } & \multirow{2}{*}{$\begin{array}{l}\text { P- } \\
\text { trend }^{c}\end{array}$} & \multirow[t]{2}{*}{$\beta(95 \% \mathrm{Cl})$ per $1 \mathrm{SD}$} & \multirow[t]{2}{*}{$P$} \\
\hline & $\overline{\mathrm{T} 1}$ & $\mathrm{~T} 2$ & T3 & & & \\
\hline \multicolumn{7}{|c|}{ Glucose metabolism markers } \\
\hline \multicolumn{7}{|c|}{ Plasma glucose, mmol/L } \\
\hline Model 1 & $4.94(4.79,5.09)$ & $4.88(4.73,5.03)$ & $4.82(4.67,4.97)$ & 0.28 & $-0.009(-0.027,0.009)$ & 0.34 \\
\hline Model 2 & $4.90(4.75,5.06)$ & $4.88(4.73,5.03)$ & $4.85(4.70,5.00)$ & 0.62 & $-0.005(-0.024,0.014)$ & 0.59 \\
\hline \multicolumn{7}{|l|}{$\mathrm{HbA} 1 \mathrm{c}, \%$} \\
\hline Model 1 & $5.59(5.50,5.69)$ & $5.63(5.54,5.73)$ & $5.71(5.61,5.81)$ & 0.10 & $0.009(-0.002,0.019)$ & 0.10 \\
\hline Model 2 & $5.61(5.52,5.71)$ & $5.63(5.53,5.72)$ & $5.69(5.60,5.79)$ & 0.28 & $0.006(-0.005,0.016)$ & 0.29 \\
\hline \multicolumn{7}{|c|}{ Liver function markers (subsample, $n=613$ ) } \\
\hline \multicolumn{7}{|c|}{ Serum GGT, U/L } \\
\hline Model 1 & $85.5(76.4,95.7)$ & $54.9(49.1,61.3)$ & $38.7(34.6,43.3)$ & $<0.001$ & $-0.32(-0.39,-0.26)$ & $<0.001$ \\
\hline Model 2 & $77.2(69.1,86.4)$ & $55.4(49.8,61.7)$ & $42.3(37.9,47.2)$ & $<0.001$ & $-0.25(-0.31,-0.18)$ & $<0.001$ \\
\hline \multicolumn{7}{|c|}{ Serum ALT, U/L } \\
\hline Model 1 & $19.4(18.0,20.9)$ & $17.3(16.0,18.6)$ & $16.5(15.3,17.8)$ & 0.004 & $-0.068(-0.112,-0.024)$ & 0.002 \\
\hline Model 2 & $18.9(17.5,20.4)$ & $17.3(16.1,18.7)$ & $16.9(15.6,18.2)$ & 0.05 & $-0.050(-0.096,-0.003)$ & 0.036 \\
\hline \multicolumn{7}{|c|}{ Serum AST, U/L } \\
\hline Model 1 & $31.5(29.0,34.3)$ & $26.9(24.7,29.1)$ & $23.9(22.0,25.9)$ & $<0.001$ & $-0.121(-0.168,-0.073)$ & $<0.001$ \\
\hline Model 2 & $30.2(27.8,32.8)$ & $26.9(24.9,29.1)$ & $24.8(22.9,26.9)$ & 0.001 & $-0.090(-0.139,-0.041)$ & $<0.001$ \\
\hline
\end{tabular}

Values for outcome variables in circulating linoleic acid tertiles are geometric means and $95 \% \mathrm{Cl}$. Values for $\beta(95 \% \mathrm{Cl})$ are natural log-transformed values; ALT Alanine aminotransferase, AST Aspartate aminotransferase, GGT gamma-glutamyl transferase

a One standard deviation of circulating linoleic acid is $3.5 \%$ total fatty acids;

${ }^{b}$ Multivariable models: Model 1: adjusted for age, sex; Model 2: model 1 plus education level, locality, smoking status, physical activity, alcohol intake, total energy intake, BMI;

c P-values for trend were obtained by assigning median value of circulating linoleic acid and this value was modelled as continuous;

dietary guidelines on dietary fat quality is based on studies in Caucasian populations [52]. The present study findings suggest that a higher dietary LA is also associated with better liver function in a black population, which support the current South African recommendation of dietary n-6 PUFA.

An important limitation of the present study is its cross-sectional design, which limits inferences on causal relationships. An additional limitation is that assessment of alcohol intake by QFFQ may not be accurate. The finding that the association of circulating LA with serum GGT was stronger in alcohol consumers than in nonconsumers warrants further investigation using a more sophisticated tool to assess alcohol intake. Another limitation of the current study is lack of insulin data. Availability of this data would add more information on insulin resistance in this population.

\section{Conclusion}

In this population of apparently healthy black South Africans, dietary and circulating LA were weakly correlated. Dietary LA and circulating LA were not significantly related to markers of glucose metabolism. However, dietary LA and in particular circulating LA were inversely related to serum GGT. This suggests that a low LA intake is related to an impaired liver function and may in this way affect long-term insulin resistance, which would explain the inverse relation between circulating LA and T2D risk observed in prospective cohort studies. The role of alcohol in the association between circulating LA and liver function warrants further research.

\section{Supplementary information}

Supplementary information accompanies this paper at https://doi.org/10. 1186/s12944-020-01318-3.

Additional file 1 Table S1. Characteristics of patients in the subsample of participants with available liver enzyme values. Table S2. Baseline characteristics of participants by locality. Table S3. Spearman's correlations of selected food groups and circulating linoleic acid. Table S4. Results from stratified analyses for associations of circulating LA with markers of liver function. Table S5. Sensitivity analyses for the crosssectional association of dietary and circulating LA with outcomes, including only participants without high alcohol intake $(n=533)$. Table S6. Sensitivity analyses for the cross-sectional association of dietary and circulating LA with outcomes, including only participants without indication of alcohol abuse $(n=540)$. Table S7. Sensitivity analyses for the crosssectional association of dietary and circulating LA with outcomes, including only participants with normal plasma glucose $(n=577)$. Figure S1. Flow chart of selection of participants. Figure S2. Circulating LA across 
tertiles of LA intake in total sample (A) and in subgroups of sex (B), age $(C)$, obesity (D), fasting plasma glucose (E) and alcohol intake (F).

\begin{abstract}
Abbreviations
ALT: Alanine aminotransferase; AST: Aspartate aminotransferase; FA: Fatty acids; GGT: Gamma-glutamyl transferase; HbA1c: Glycosylated hemoglobin; HIV: Human immunodeficiency virus; LA: Linoleic acid; PAl: Physical activity index; PUFA: Polyunsaturated fatty acids; PURE-NWP-SA: Prospective Urban Rural Epidemiology North-West Province South Africa; QFFQ: Quantified food-frequency questionnaire; T2D: Type 2 diabetes
\end{abstract}

\section{Acknowledgments}

The authors would like to thank all supporting staffs and participants of the PURE study and in particular: 1) PURE-South Africa: Prof. A. Kruger (posthumous), Prof. M. Greeff, Ms. P.G. Molaudzi, Ms. V. Kruger, Ms. J. Brits, Ms. P. Jardim working in the Africa Unit for Transdisciplinary Health Research (AUTHeR), Faculty of Health Sciences, North-West University, Potchefstroom, South Africa, as well as all the field workers over the years; Ms. M. Maritz (Hypertension in Africa Research Team) for her contribution towards finalizing the mortality data. 2) PURE International: Prof. S. Yusuf and the PURE project office staff at the Population Health Research Institute (PHRI), Hamilton Health Sciences and McMaster University, ON, Canada. Any opinion, finding and conclusion or recommendation expressed in this material is that of the authors and the South African National Research Foundation does not accept any liability in this regard.

\section{Authors' contributions}

HSK, IMK, TVZ and CMS designed the research. KP, LKK, JMG and HSK conducted the research. KP performed the statistical analyses; KP wrote the draft paper. All authors interpreted the results and critically revised the manuscript for intellectual content. CMS had overall responsibility for the research. All authors approved the final manuscript for publication.

\section{Funding}

This research was supported by the Netherlands Organization for Scientific Research (NWO) through its Graduate Programme on Food Structure, Digestion and Health and Upfield ${ }^{\mathrm{TM}}$. Fatty acids measurement was funded by Unilever. PURE South Africa study was supported by South Africa Netherlands Research Programme on Alternatives in Development (08/15), South African National Research Foundation (NRF GUN numbers 2069139 and FA2006040700010; FA2007042600011), South African Medical Research Council, North-West University, Potchefstroom, South Africa and the Population Health Research Institute, ON, Canada.

\section{Availability of data and materials}

The data that support the findings of this study are available from PURE South Africa study investigators but restrictions apply to the availability of these data and so are not publicly available. Data are however available from the authors upon reasonable request and with permission of the Health Research Ethics Committee of North-West University.

\section{Ethics approval and consent to participate}

All participants gave written consent to participation and the study was approved by the Ethics Committee of the North-West University.

\section{Consent for publication}

\section{Not applicable}

\section{Competing interests}

This research was supported in part by Upfield. AJW and PLZ are employed by Unilever, the Netherlands. Unilever is a producer of food consumer products. It divested its spreads business, which has operated since July 2018 under the name Upfield. JMG received financial support from Unilever for epidemiological studies of dietary and circulating fatty acids. The funders had no role in the design of the study, collection and analysis of data and decision to publish. No other potential conflicts of interest relevant to this article were reported.

\section{Author details}

'Division of Human Nutrition and Health, Wageningen University, Wageningen, The Netherlands. ${ }^{2}$ Unilever R\&D, Foods Innovation Centre, Wageningen, the Netherlands. ${ }^{3}$ Centre of Excellence for Nutrition, Faculty of Health Sciences, North-West University, Potchefstroom, South Africa. ${ }^{4}$ Africa Unit for Transdisciplinary Health Research, Faculty of Health Sciences, North-West University, Potchefstroom, South Africa.

Received: 27 March 2020 Accepted: 10 June 2020

Published online: 16 June 2020

\section{References}

1. Wu JHY, Marklund M, Imamura F, Tintle N, Ardisson Korat AV, de Goede J, et al. Omega-6 fatty acid biomarkers and incident type 2 diabetes: pooled analysis of individual-level data for 39740 adults from 20 prospective cohort studies. Lancet Diabetes Endocrinol. 2017;5:965-74.

2. Hodge AM, English DR, O'Dea K, Sinclair AJ, Makrides M, Gibson RA, et al. Plasma phospholipid and dietary fatty acids as predictors of type 2 diabetes: interpreting the role of linoleic acid. Am J Clin Nutr. 2007;86(1):189-97.

3. Patel PS, Sharp SJ, Jansen E, Luben RN, Khaw K-T, Wareham NJ, et al. Fatty acids measured in plasma and erythrocyte-membrane phospholipids and derived by food-frequency questionnaire and the risk of new-onset type 2 diabetes: a pilot study in the European Prospective Investigation into Cancer and Nutrition (EPIC)-Norfolk cohort. Am J Clin Nutr. 2010;92(5):121422.

4. Kröger J, Zietemann V, Enzenbach C, Weikert C, Jansen EH, Döring F, et al. Erythrocyte membrane phospholipid fatty acids, desaturase activity, and dietary fatty acids in relation to risk of type 2 diabetes in the European Prospective Investigation into Cancer and Nutrition-Potsdam study. Am J Clin Nutr. 2010;93(1):127-42.

5. Zong G, Liu G, Willett WC, Wanders AJ, Alssema M, Zock PL, et al. Associations between linoleic acid intake and incident type 2 diabetes among U.S. men and women. Diabetes Care. 2019;42(8):1406-13.

6. Fekete K, Györei E, Lohner S, Verduci E, Agostoni C, Decsi T. Long-chain polyunsaturated fatty acid status in obesity: a systematic review and metaanalysis. Obes Rev. 2015;16(6):488-97.

7. Lankinen M, Uusitupa M, Schwab U. Genes and dietary fatty acids in regulation of fatty acid composition of plasma and erythrocyte membranes. Nutrients. 2018;10(11):1785.

8. Park H, Hasegawa G, Shima T, Fukui M, Nakamura N, Yamaguchi K, et al. The fatty acid composition of plasma cholesteryl esters and estimated desaturase activities in patients with nonalcoholic fatty liver disease and the effect of long-term ezetimibe therapy on these levels. Clin Chim Acta. 2010; 411(21):1735-40.

9. Rosqvist F, Bjermo H, Kullberg J, Johansson L, Michaëlsson $\mathrm{K}$, Ahlström $\mathrm{H}$, et al. Fatty acid composition in serum cholesterol esters and phospholipids is linked to visceral and subcutaneous adipose tissue content in elderly individuals: a cross-sectional study. Lipids Health Dis. 2017;16(1):68.

10. Imamura F, Micha R, Wu JHY, de Oliveira Otto MC, Otite FO, Abioye Al, et al. Effects of saturated fat, polyunsaturated fat, monounsaturated fat, and carbohydrate on glucose-insulin homeostasis: a systematic review and meta-analysis of randomised controlled feeding trials. PLoS Med. 2016;13(7): e1002087.

11. Wanders AJ, Blom WAM, Zock PL, Geleijnse JM, Brouwer IA, Alssema M. Plant-derived polyunsaturated fatty acids and markers of glucose metabolism and insulin resistance: a meta-analysis of randomized controlled feeding trials. BMJ Open Diabetes Res Care. 2019;7(1):e000585.

12. George ES, Forsyth A, Itsiopoulos C, Nicoll AJ, Ryan M, Sood S, et al. Practical dietary recommendations for the prevention and management of nonalcoholic fatty liver disease in adults. Adv Nutr. 2018;9(1):30-40.

13. Johnson GH, Fritsche K. Effect of dietary linoleic acid on markers of inflammation in healthy persons: A systematic review of randomized controlled trials. J Acad Nutr Diet. 2012;112(7):1029-41.e15.

14. Su H, Liu R, Chang M, Huang J, Wang X. Dietary linoleic acid intake and blood inflammatory markers: a systematic review and meta-analysis of randomized controlled trials. Food Funct. 2017;8(9):3091-103.

15. Mathias RA, Sergeant S, Ruczinski I, Torgerson DG, Hugenschmidt CE, Kubala $\mathrm{M}$, et al. The impact of FADS genetic variants on $\omega 6$ polyunsaturated fatty acid metabolism in African Americans. BMC Genet. 2011;12(1):50. 
16. Vorster HH, Kruger A, Wentzel-Viljoen E, Kruger HS, Margetts BM. Added sugar intake in South Africa: findings from the adult Prospective Urban and Rural Epidemiology cohort study. Am J Clin Nutr. 2014;99(6):1479-86.

17. Willett W. Nutritional epidemiology. 3rd ed. New York: Oxford University Press; 2013.

18. Maclntyre UE, Venter CS, Vorster HH. A culture-sensitive quantitative food frequency questionnaire used in an African population: 1. Development and reproducibility. Public Health Nutr. 2001;4(1):53-62.

19. Maclntyre UE, Venter CS, Vorster HH. A culture-sensitive quantitative food frequency questionnaire used in an African population: 2. Relative validation by 7-day weighed records and biomarkers. Public Health Nutr. 2001;4(1):63-71.

20. Venter CS, Maclntyre UE, Vorster HH. The development and testing of a food portion photograph book for use in an African population. J Hum Nutr Diet. 2000;13(3):205-18.

21. Wolmarans P, Danster N. South African Medical Research Council. Condensed food composition tables for South Africa. South African Medical Research Council: Cape Town; 2010.

22. Folch J, Lees M, Stanley GHS. A simple method for the isolation and purification of total lipides from animal tissues. J Biol Chem. 1957;226(1):497-509.

23. Baumgartner J, Smuts CM, Malan L, Kvalsvig J, van Stuijvenberg ME, Hurrel RF, et al. Effects of iron and n-3 fatty acid supplementation, alone and in combination, on cognition in school children: a randomized, double-blind, placebo-controlled intervention in South Africa. Am J Clin Nutr. 2012;96(6): 1327-38.

24. Kruger $\mathrm{H}$, Venter $\mathrm{C}$, Steyn $\mathrm{H}$. A standardised physical activity questionnaire for a population in transition: the THUSA study. Afr J Phys Health Educ Recreat Dance. 2000;6:54-64

25. Kruger HS, Venter CS, Vorster HH. Physical inactivity as a risk factor for cardiovascular disease in communities undergoing rural to urban transition: the THUSA study. Cardiovasc J S Afr. 2003;14(1):16-23.

26. Pisa P, Kruger A, Vorster H, Margetts B, Loots Du T. Alcohol consumption and cardiovascular disease risk in an African population in transition: the Prospective Urban and Rural Epidemiology (PURE) study. South Afr J Clin Nutr. 2010;23(sup2):29-37.

27. Schutte AE, Schutte R, Huisman HW, van Rooyen JM, Fourie CM, Malan NT, et al. Are behavioural risk factors to be blamed for the conversion from optimal blood pressure to hypertensive status in black South Africans? A 5year prospective study. Int J Epidemiol. 2012;41(4):1114-23.

28. van Rooyen Y, Schutte AE, Huisman HW, Eloff FC, Du Plessis JL, Kruger A, et al. Inflammation as possible mediator for the relationship between lung and arterial function. Lung. 2016;194(1):107-15.

29. Sathiyakumar V, Park J, Golozar A, Lazo M, Quispe R, Guallar E, et al. Fasting versus nonfasting and low-density lipoprotein cholesterol accuracy. Circulation. 2018;137(1):10-9.

30. Micha R, Khatibzadeh S, Shi P, Fahimi S, Lim S, Andrews KG, et al. Global, regional, and national consumption levels of dietary fats and oils in 1990 and 2010: A systematic analysis including 266 country-specific nutrition surveys. BMJ. 2014; 348:92272.

31. Wanders AJ, Alssema M, de Koning EJP, le Cessie S, de Vries JH, Zock PL, et al. Fatty acid intake and its dietary sources in relation with markers of type 2 diabetes risk: the NEO study. Eur J Clin Nutr. 2017;71(2):245-51.

32. Heikkilä HM, Schwab U, Krachler B, Männikkö R, Rauramaa R. Dietary associations with prediabetic states - the DR's EXTRA study (ISRCTN45977199). Eur J Clin Nutr. 2012;66(7):819-24.

33. Julibert A, MdM B, Bouzas C, Martínez-González MÁ, Salas-Salvadó J, Corella $D$, et al. Total and subtypes of dietary fat intake and its association with components of the metabolic syndrome in a mediterranean population at high cardiovascular risk. Nutrients. 2019;11(7):1493.

34. Brown TJ, Brainard J, Song F, Wang X, Abdelhamid A, Hooper L. Omega-3, omega-6, and total dietary polyunsaturated fat for prevention and treatment of type 2 diabetes mellitus: systematic review and meta-analysis of randomised controlled trials. BMJ. 2019;366:14697.

35. Cabout M, Alssema M, Nijpels G, Stehouwer CDA, Zock PL, Brouwer IA, et al. Circulating linoleic acid and alpha-linolenic acid and glucose metabolism: the Hoorn study. Eur J Nutr. 2017;56:2171-80.

36. Kahn SE, Cooper ME, Del Prato S. Pathophysiology and treatment of type 2 diabetes: perspectives on the past, present, and future. Lancet. 2014; 383(9922):1068-83.

37. Wallace TM, Utzschneider KM, Tong J, Carr DB, Zraika S, Bankson DD, et al. Relationship of liver enzymes to insulin sensitivity and intra-abdominal fat. Diabetes Care. 2007;30(10):2673-8.
38. Thamer C, Tschritter O, Haap M, Shirkavand F, Machann J, Fritsche A, et al. Elevated serum GGT concentrations predict reduced insulin sensitivity and increased intrahepatic lipids. Horm Metab Res. 2005;37(04):246-51.

39. Lee D-H, Steffen LM, Jacobs DR Jr. Association between serum Yglutamyltransferase and dietary factors: the coronary artery risk development in young adults (CARDIA) study. Am J Clin Nutr. 2004;79(4): $600-5$.

40. Bjermo H, lggman D, Kullberg J, Dahlman I, Johansson L, Persson L, et al. Effects of n-6 PUFAs compared with SFAs on liver fat, lipoproteins, and inflammation in abdominal obesity: a randomized controlled trial. Am J Clin Nutr. 2012:95(5):1003-12.

41. Jacobs S, Schiller K, Jansen EH, Boeing H, Schulze MB, Kröger J. Evaluation of various biomarkers as potential mediators of the association between $\Delta 5$ desaturase, $\Delta 6$ desaturase, and stearoyl-CoA desaturase activity and incident type 2 diabetes in the European Prospective Investigation into Cancer and Nutrition-Potsdam study. Am J Clin Nutr. 2015;102(1):155-64.

42. Kishino T, Watanabe K, Urata T, Takano M, Uemura T, Nishikawa K, et al. Visceral fat thickness in overweight men correlates with alterations in serum fatty acid composition. Clin Chim Acta. 2008;398(1):57-62.

43. Wang Y, Jones Voy B, Urs S, Kim S, Soltani-Bejnood M, Quigley N, et al. The human fatty acid synthase gene and de novo lipogenesis are coordinately regulated in human adipose tissue. J Nutr. 2004;134(5):1032-8.

44. Lee D-H, Blomhoff $\mathrm{R}$, Jacobs DR. Is serum gamma glutamyltransferase a marker of oxidative stress? Free Radic Res. 2004;38(6):535-9.

45. Pertiwi K, Kok DE, Wanders AJ, de Goede J, Zock PL, Geleijnse JM. Circulating n-3 fatty acids and linoleic acid as indicators of dietary fatty acid intake in post-myocardial infarction patients. Nutr Metab Cardiovasc Dis. 2019;29(4):343-50.

46. Gao B, Bataller R. Alcoholic liver disease: pathogenesis and new therapeutic targets. Gastroenterology. 2011;141(5):1572-85.

47. Warnet JM, Cambien F, Vernier V, Pecoraro M, Flament C, Ducimetiere P, et al. Relation between consumption of alcohol and fatty acids esterifying serum cholesterol in healthy men. BMJ. 1985:290(6485):1859-61.

48. Cambien F, Warnet J-M, Vernier V, Ducimetiére P, Jacqueson A, Flament C, et al. An epidemiologic appraisal of the associations between the fatty acids esterifying serum cholesterol and some cardiovascular risk factors in middleaged men. Am J Epidemiol. 1988;127(1):75-86.

49. Laguzzi F, Risérus $U$, Marklund $M$, Vikström $M$, Sjögren $P$, Gigante $B$, et al. Circulating fatty acids in relation to alcohol consumption: Cross-sectional results from a cohort of 60-year-old men and women. Clin Nutr. 2018;37(6, Part A):2001-10.

50. Setlalentoa B, Pisa P, Thekisho G, Ryke E, Loots Du T. The social aspects of alcohol misuse/abuse in South Africa. South Afr J Clin Nutr. 2010;23(sup2): $11-5$.

51. Schneider ALC, Lazo M, Ndumele CE, Pankow JS, Coresh J, Clark JM, et al. Liver enzymes, race, gender and diabetes risk: the Atherosclerosis Risk in Communities (ARIC) study. Diabet Med. 2013;30(8):926-33.

52. Smuts CM, Wolmarans $P$. 10. The importance of the quality or type of fat in the diet: a food-based dietary guideline for South Africa. South Afr J Clin Nutr. 2013;26(S):S87-99.

\section{Publisher's Note}

Springer Nature remains neutral with regard to jurisdictional claims in published maps and institutional affiliations.

Ready to submit your research? Choose BMC and benefit from:

- fast, convenient online submission

- thorough peer review by experienced researchers in your field

- rapid publication on acceptance

- support for research data, including large and complex data types

- gold Open Access which fosters wider collaboration and increased citations

- maximum visibility for your research: over $100 \mathrm{M}$ website views per year

At $\mathrm{BMC}$, research is always in progress.

Learn more biomedcentral.com/submissions 